\title{
Chronic diarrhea associated with persistent norovirus excretion in patients with chronic lymphocytic leukemia: report of two cases
}

\author{
Todd Capizzi, Grace Makari-Judson, Richard Steingart and Wilson C Mertens
}

\begin{abstract}
Background: Chronic diarrhea in patients treated with immunosuppressive agents or suffering from immunosuppressive disease can represent a diagnostic and therapeutic challenge to the clinician. Norovirus infection, a major cause of acute epidemic diarrhea, has been described as a cause of chronic diarrhea in patients who are immunosuppressed, including transplant recipients and the very young.

Case presentations: We describe two patients, a 64 year-old man and a 59 year-old woman, both suffering from chronic lymphocytic leukemia and hypogammaglobulinemia, who developed chronic diarrhea resistant to therapy. In both cases, after months of symptoms, persistent norovirus infection-documented by repeatedly-positive highsensitivity stool enzyme immunoassay-was found to be the cause. Both patients died with active diarrheal symptoms.
\end{abstract}

Conclusions: We describe the first cases of advanced chronic lymphocytic leukemia to suffer from chronic symptomatic norovirus infection. Clinicians caring for such patients, particularly those with concomitant hypogammaglobulinema, who have chronic unexplained diarrhea, should consider norovirus infection in the differential diagnosis.

\section{Background}

Norovirus is the major cause of epidemic viral gastroenteritis worldwide, affecting all age groups [1]. The disease is generally acute and self limited. However, there have been reported cases of chronic norovirus infections, especially in the setting of long-term immunosuppression, such as organ transplantation [2,3]. These infections can be debilitating, causing severe wasting and malnutrition, and can be confused with graft-versus-host reactions. Chronic lymphocytic leukemia (CLL) can be associated with defective immunity, leading to severe, recurrent infections $[4,5]$. We report two patients with CLL and hypogammaglobulinemia affected by chronic norovirus infection.

\section{Case Presentation First Case}

The first patient, a 64 year old man diagnosed with CLL noted to be hypogammaglobulinemic since 2006, began

\footnotetext{
* Correspondence: wilson.mertens@baystatehealth.org

Baystate Regional Cancer Program/Tufts University School of Medicine, 3400 Main Street, Springfield, MA 01107 USA
}

having profuse, watery, non-bloody diarrhea starting in 2007 , presenting initially with nausea and fever (100.5 F) which persisted for a week. The patient did not report exposure to others with diarrhea. He experienced up to 12 bowel movements daily, and was treated with intravenous immunoglobulin, octreotide, nitazoxanide, mesalamine and antimotility agents (including loperamide and diphenoxylate/atropine) without symptomatic improvement. Total parenteral nutrition (TPN) was initiated and continued for almost two years; a period of fasting while on TPN did not result in a reduction in stool frequency. An extensive gastroenterologic evaluation, including stool for leukocytes (none seen), fecal fat measurement (normal), gliadin antibody assay (negative), endoscopy, capsule endoscopy, and colonoscopy were performed; colonic biopsies demonstrated focal active colitis with an area of detached mucus and neutrophilic exudate but with preserved villi, while duodenal biopsy yielded normal mucosa. Extensive stool evaluation for non-viral pathogens (including C. difficle, Camplyobacter spp., Salmonella spp., and Yersinia; cryptosporidium, 
microsporidium and trichrome stains; as well as Giardia lamblia [including antigen assay] and ova and parasite evaluation) and hormonal assays (gastrin, vasoactive intestinal polypeptide, and calcitonin) failed to yield a diagnosis. After a year of chronic diarrhea, norovirus was identified in stool by enzyme immunoassay (EIA; RIDASCREEN $^{\circledR}$ norovirus enzyme immunoassay; R-Biopharm, Dusseldorf, Germany) [6] in July 2008, both at our institution and at another teaching facility. His immunoglobulins at that time were profoundly low (IgG $141 \mathrm{mg} / \mathrm{dl}$ [normal: 700-1600 mg/dl]; IgA $11 \mathrm{mg} / \mathrm{dl}$ [normal: $70-400 \mathrm{mg} / \mathrm{dl}$ ]; IgM $6 \mathrm{mg} / \mathrm{dl}$ [normal 40-230 $\mathrm{mg} / \mathrm{dl}]$ ). Stool studies for norovirus remained positive in September and December 2008, and again in February 2009. The patient expired in February 2009 from pneumonia and septic shock after receiving one cycle of rituximab, cyclophosphamide, vincristine and prednisone. As members of his family had not contracted diarrhea during his long undiagnosed course, no effort was made to isolate the patient but handwashing and attention to hygiene was advised.

\section{Second Case}

The second patient, a 59 year old woman diagnosed with CLL in 1999 was initially found to be hypogammaglobulinemic in 2006 without prior history of recurrent infection. She had received multiple chemotherapeutic interventions over the years; her most recent treatment regimen consisted of rituximab and corticosteroids. The patient commenced intravenous immunoglobulin therapy in January 2009, following recurrent hospitalizations for pneumonia (at that time IgG $512 \mathrm{mg} / \mathrm{dl}$, IgA $<7$ $\mathrm{mg} / \mathrm{dl}$, IgM $30 \mathrm{mg} / \mathrm{dl}$ ). In February 2009, after members of her immediate family experienced an undiagnosed, self-limited diarrheal illness accompanied by fever and vomiting, the patient developed bloating and daily watery, non-bloody and non-purulent diarrhea that was predominantly nocturnal (with 3-4 episodes nightly), and weight loss. Her initial presentation was associated with fever, but this abated after 10 days; she did not experience nausea or vomiting. Supportive measures (antimotility agents as noted above, active cultures, avoidance of lactose containing products, cholestyramine, and octreotide) were ineffective, and she began to require frequent infusions of intravenous fluids to combat dehydration. Infectious workup of her diarrhea revealed stool positive for the norovirus antigen (by EIA) on three occasions: March, May, and September 2009. Further gastroenterological evaluation, including endoscopy/colonoscopy, and stool evaluation for other infectious agents (culture, ova and parasite evaluation, trichrome stain, cryptosporidium and microsporidium stains, and Giardia lamblia antigen assay) failed to reveal another cause for her diarrhea. Duodenal biopsy in April 2009 revealed mild, active duodenitis, but no other specific diagnosis; random colonic biopsy yielded normal colonic mucosa. The patient had continuing symptoms for 11 months, had lost $10 \mathrm{~kg}$ despite TPN and continued to have problems with malnutrition. Diarrhea continued despite a period of fasting while on TPN. No specific treatment was offered to control the norovirus; the patient ultimately developed respiratory failure due to bilateral lobar pneumonia and died in October 2010. As her family had recovered from their diarrheal illness and had not had a recurrence during her prolonged course, no attempt to isolate the patient was made, but advice on handwashing and hygiene was given.

\section{Discussion}

Chronic diarrhea, defined as symptoms persisting for 2 or more weeks, has a myriad of causes including infection, medication, malignancy, and inflammatory conditions. Norovirus, a calicivirus, is associated with acute gastroenteritis in humans, and is spread through the fecal-oral route, either by consumption of contaminated food or water or by direct person-person spread [1]. After an incubation period of 24 to 48 hours, patients often present with acute onset vomiting, watery nonbloody diarrhea with abdominal cramps, and nausea. Dehydration is the most common complication, especially in children and the elderly. Symptoms of this infection usually persist 24 to 60 hours, and the disease is almost always self-limited. However, hospital patient populations have been described with longer mean duration of illness, lasting 80 hours [1,3]. In the elderly, while acute symptoms abate after three to four days, other symptoms such as thirst, anorexia, lethargy, and vertigo can persist for up to 19 days, leading to delayed recovery and other complications $[7,8]$. The diagnosis is usually made with reverse transcriptase-polymerase chain reaction (RT-PCR) or EIA to detect the presence of norovirus in stool or emesis samples. The virus can be found in stool samples as late as 3 to 8 weeks after recovery in community based outbreaks in otherwise healthy individuals, with increasing age and children less than 2 years of age associated with long term shedding; however, no significant increase in symptoms has been found as viral concentrations diminish over time [8-11].

Gastrointestinal symptoms resulting from a variety of viral, bacterial, or parasitic pathogens, or from drug therapy or graft-versus-host disease, are common causes of morbidity and mortality in immunocompromised hosts, particularly those with solid organ transplantation requiring chronic immunosuppressant medication and patients undergoing systemic chemotherapy, or those infected with human immunodeficiency virus (see Table 1) [12]. Hypogammaglobulinemia in particular appears to be a 
Table 1 Causes of chronic diarrhea in patients with immunodeficiency $[18,19]$

\begin{tabular}{|c|c|c|}
\hline \multirow[t]{5}{*}{ Infectious Causes } & Bacteria & $\begin{array}{l}\text { Escherichia coli } \\
\text { Salmonella } \\
\text { Shigella } \\
\text { Campylobacter jejuni } \\
\text { Clostridium difficile } \\
\text { Mycoabacterium tuberculosis } \\
\text { Mycobacterium avium complex (MAC) }\end{array}$ \\
\hline & Parasites & $\begin{array}{l}\text { Cryptosporidium } \\
\text { Microsporidium } \\
\text { Isospora Belli } \\
\text { Giardia lamblia } \\
\text { Entamoeba histolytica }\end{array}$ \\
\hline & Viral Infections & $\begin{array}{l}\text { Cytomegalovirus } \\
\text { Herpes virus } \\
\text { HIV (AIDS enteropathy) } \\
\text { Rotavirus } \\
\text { Astrovirus } \\
\text { Norovirus }\end{array}$ \\
\hline & Fungus & Candida \\
\hline & Other Causes & Invasive bacterial enteritis \\
\hline \multirow[t]{3}{*}{ Non-Infectious Causes } & Treatment-related & $\begin{array}{l}\text { Radiation enteritis-acute/chronic } \\
\text { Graft-versus-host disease } \\
\text { Chemotherapy-fluoropyrimidines, irinotecan } \\
\text { Other medication side-effects }\end{array}$ \\
\hline & Malabsorption & $\begin{array}{l}\text { Small bowel bacterial overgrowth } \\
\text { Lymphoma } \\
\text { Kaposi sarcoma } \\
\text { Pancreatic insufficiency-cytomegalovirus, MAC, medications }\end{array}$ \\
\hline & Other Causes & $\begin{array}{l}\text { Irritable bowel syndrome } \\
\text { Functional disorders }\end{array}$ \\
\hline
\end{tabular}

contributing factor in recurring cytomegalovirus infection in organ transplant patients, leading to severe gastrointestinal disease [12].

More prolonged shedding and higher concentrations of norovirus have also been described in immunocompromised hosts, including congenital conditions, such as severe combined immunodeficiency and T-cell immunodeficiency, and acquired immunodeficiency, such as the setting of transplantation and patients with solid tumors receiving cytotoxic chemotherapy [1-3,12-14]. One study of pediatric oncology patients described norovirus shedding for durations exceeding 100 days-one patient had detectable norovirus detected for 420 days-leading to severe weight loss and growth retardation [13]. The case of a patient infected with human immunodeficiency virus (HIV) experiencing chronic norovirus infection and persistent, voluminous diarrhea treated with intravenous immunoglobulin was reported recently; no significant improvement was seen, although the patient was not noted to be hypogammaglobulinemic [14].
Norovirus appears to be a rare cause of chronic diarrhea, and its diagnosis is reliant on stool testing for presence of the virus, as characteristic pathological findings, simpler stool culture or routinely-applied clinical screening assays are lacking; consequently, it is conceivable that chronic norovirus-associated diarrhea may be more common than currently appreciated in patients with a variety of immunodeficiency disorders. Additionally, specific and effective therapies are not currently available for this condition. In our two cases intravenous gamma globulin did not result in amelioration of symptoms or eradication of the virus.

Patients with CLL have a number of immune system defects that evolve over time, including disordered B-cell function with decreased production of normal B-cells and abnormal production of immune globulins [15], suppressed T-cell function [16], and ultimately hypogammaglobulinemia and neutropenia in advanced cases [17]. Which defect, or combination of defects, is crucial to the development of persistent norovirus infection is 
unknown. In the two present cases, hypogammaglobulinemia was a common finding; the first case had not yet been treated with chemotherapy or anti CD-20 monoclonal antibody therapy at the time of development of norovirus-associated diarrhea.

\section{Conclusions}

While CLL associated with hypogammaglobulinemia is commonly linked to recurring infection, [5] our literature search failed to find other reports of patients with CLL suffering from persistent diarrhea as a result of chronic norovirus infection. Enteric viral infections, including norovirus, should be considered in the differential diagnosis of severe, persistent diarrhea in all immunocompromised patients-including CLL-that may result in severe morbidity and mortality in those affected.

\section{Consent}

Written informed consent was obtained from the patients' families for publication of these case reports. Copies of the written consents are available for review by the Editor-in-Chief of this journal.

\section{Authors' contributions}

TC was responsible for assembling the cases and background information, and writing the manuscript. GMJ, RS and WCM participated in reviewing the cases, drafting and editing the manuscript, and obtaining consent for publication. GMJ conceived the study. All authors read and approved the final manuscript.

\section{Authors' Information}

TC is a fellow in hematology oncology at Baystate Regional Cancer Program. GMJ is medical director, Comprehensive Breast Center; RS is medical director of adult hematology; and WCM is medical director, Cancer Services; all at Baystate Regional Cancer Program. GMJ and WCM are associate professors of medicine, and RS assistant professor of medicine, at Tufts University School of Medicine.

\section{Declaration of Competing interests}

The authors declare that they have no competing interests.

Received: 30 August 2010 Accepted: 17 May 2011

Published: 17 May 2011

\section{References}

1. Glass RI, Parashar UD, Estes MK: Norovirus gastroenteritis. N Engl J Med 2009, 361:1776-1785.

2. Lee BE, Pang XL, Robinson JL, Bigam D, Monroe SS, Preiksaitis JK: Chronic norovius and adenovirus infection in a solid organ transplant recipient. Pediatr Infect Dis J 2008, 27:360-362.

3. Kaufman SS, Chatterjee NK, Fuschino ME, Morse DL, Morotti RA, Magid MS, Gondolesi GE, Florman SS, Fishbein TM: Characteristics of human calicivirus enteritis in intestinal transplant recipients. J Pediatr Gastroenterol Nutr 2005, 40:328-333.

4. Ravandi F, O'Brien S: Immmune defects in chronic lymphocytic leukemia. Cancer Immunol Immunother 2006, 55:197-209.

5. Morrison VA: Infectious complications in patients with chronic lymphocytic leukemia: pathogenesis, spectrum of infection, and approaches to prophylaxis. Clin Lymphoma Myeloma 2009, 9:365-370.

6. Castriciano S, Luinstra K, Petrich A, Smieja M, Lee C, Jang D, Portillo E, Chernesky M, et al: Comparison of the RIDASCREEN ${ }^{\circledR}$ norovirus enzyme immunoassay to IDEIA NLV GI/GII by testing stools also assayed by RTPCR and electron microscopy. J Virol Method 2007, 141:216-219.

7. Lopman BA, Reacher MH, Vipond IB, Sarangi J, Brown DW: Clinical manifestation of norovirus gastroenteritis in health care settings. Clin Infect Dis 2004, 39:318-324.

8. Goller JL, Dimitriadis A, Tan A, Kelly H, Marshall JA: Long-term features of norovirus gastroenteritis in the elderly. J Hosp Infect 2004, 58:286-291.

9. Rockx B, De Wit M, Vennema H, Vinné J, De Bruin E, Van Duynhoven Y, Koopmans M: Natural history of human calicivirus infection: a prospective cohort study. Clin Infect Dis 2002, 35:246-253.

10. Atmar RL, Opekun AR, Gilger MA, Estes MK, Crawford SE, Neill FH, Graham DY: Norwalk virus shedding after experimental human infection. Emerg Infect Dis 2008, 14:1553-1557.

11. Murata T, Katsushima N, Mizuta K, Muraki Y, Hongo S, Matsuzaki Y: Prolonged norovirus shedding in infants $<$ or $=6$ months of age with gastroenteritis. Pediatr Infect Dis J 2007, 26:46-49.

12. Thom K, Forrest G: Gastrointestinal infections in immunocompromised hosts. Curr Opin Gastroenterol 2006, 22:18-23.

13. Ludwig A, Adams O, Laws HJ, Schroten H, Tenenbaum T: Quantitative detection of norovirus excretion in pediatric patients with cancer and prolonged gastroenteritis and shedding of norovirus. J Med Virol 2008, 80:1461-1467.

14. Wingfield T, Gallimore Cl, Xerry J, Gray JJ, Klapper P, Guiver M, Blanchard TJ: Chronic norovirus infection in an HIV-positive patient with persistent diarrhea: a novel cause. J Clin Virol 2010, 49:219-222.

15. Motta M, Chiarini M, Ghidini C, Zanotti C, Lamorgese C, Caimi L, Rossi G, Imberti L: Quantification of newly produced B and T cells in untreated chronic lymphocytic leukemia patients. J Transl Med 2010, 8:111.

16. Riches JC, Ramsay AG, Gribben JG: T-cell function in chronic lymphocytic leukemia. Semin Cancer Biol 2010, 20:431-438.

17. Dasanu CA: Intrinsic and treatment-related immune alterations in chronic lymphocytic leukemia and their impact for clinical practice. Expert Opin Pharmacother 2008, 9:1481-1494.

18. Cox GJ, Matsui SM, Lo RS, Hinds M, Bowden RA, Hackman RC, Meyer WG, Mori M, Tarr PI, Oshiro LS, Ludert JE, Meyers JD, McDonald GB: Etiology and outcome of diarrhea after marrow transplantation: a prospective study. Gastroenterology 1994, 107:1398-1408.

19. Beatty GW: Diarrhea in patients infected with HIV presenting to the Emergency Department. Emerg Med Clin N Am 2010, 28:299-310.

\section{Pre-publication history}

The pre-publication history for this paper can be accessed here: http://www.biomedcentral.com/1471-2334/11/131/prepub

\section{doi:10.1186/1471-2334-11-131}

Cite this article as: Capizzi et al:: Chronic diarrhea associated with persistent norovirus excretion in patients with chronic lymphocytic leukemia: report of two cases. BMC Infectious Diseases 2011 11:131.

\section{Submit your next manuscript to BioMed Central and take full advantage of:}

- Convenient online submission

- Thorough peer review

- No space constraints or color figure charges

- Immediate publication on acceptance

- Inclusion in PubMed, CAS, Scopus and Google Scholar

- Research which is freely available for redistribution 